\title{
Small Scale Contractors in Africa's Emerging Markets: The Case of South Africa
}

\author{
George Hove \\ Independent Consultant, Johannesburg, South Africa \\ Email:71759956@mylife.unisa.ac.za
}

How to cite this paper: Hove, G. (2016) Small Scale Contractors in Africa's Emerging Markets: The Case of South Africa. Open Journal of Business and Management, 4, 649-658.

http://dx.doi.org/10.4236/ojbm.2016.44065

Received: August 20, 2016

Accepted: September 3, 2016

Published: September 7, 2016

Copyright $\odot 2016$ by author and Scientific Research Publishing Inc. This work is licensed under the Creative Commons Attribution International License (CC BY 4.0).

http://creativecommons.org/licenses/by/4.0/

\begin{abstract}
In South Africa, the development of Small scale emerging contractors (SSECs) has become vital to bring about economic prosperity and the government has prioritised the advancement of SSECs as the vehicle towards achieving economic growth, development and job creation for previously disadvantaged people. This paper reviewed related construction studies on small scale contractors and highlighted unique roles and challenges as they relate to emerging construction businesses. The paper established that the main challenges affecting SSECs included finance, skills shortage, enabling environment and competition. Based on data analysis, it is imperative for the South African government to develop a clear and more comprehensive small business contracting policies that would enhance growth and profitability of Small scale emerging contractors.
\end{abstract}

\section{Keywords}

Small Scale Emerging Contractor, South Africa, Emerging Market

\section{Introduction}

In every economy, the construction industry plays an important role to improve the socioeconomic conditions of its citizens [1]. The industry is mainly dominated by clients, contractors, consultants, shareholders and regulators as its key stakeholders. In this paper, construction industry is guided by [2] who defined it as "an economic entity which plans, designs, constructs, alters, maintains, repairs and eventually demolishes buildings of various kinds", this includes civil work, architectural and structural works. The industry is a project-based sector within which individual projects are custom built to client specification [3]. According to [4], a contractor is a person or body of persons who undertake/s to execute and complete construction works. 
In South Africa, the government has prioritised entrepreneurship and the advancement of Small, Medium and Micro-sized Enterprises (SMMEs) which have been considered as a catalyst to achieving economic growth and development [5]. In the construction industry, the small scale emerging contractors (SSECs) have received high priority from the government as they constitute the largest segment of that industry. Although small in size, the SSECs are vital to the performance of the industry and the economy at large. In view of this background, this paper examines the role played by SSECs in the development of the South African economy. The paper also goes further and revisits the challenges encountered by SSECs that impede growth and profitability.

\section{Defining Small Scale Contractor}

In this study, Small Scale Contractor refers to small business which is owned (at least $50 \%$ ), managed and controlled by previously disadvantaged persons and which is overcoming business impediments arising from the legacy of apartheid [6]. This refers to small-scale construction enterprises in CIDB graded 2 - 5. CIDB grading system provides a framework for matching contractors and contracts [7]. Through the grading system, CIDB regulates the tenders, where contractors in grade 9 bid for projects with unlimited values and those in grade 8 bid for projects between R40 - 130 million [7]. Contractors that fall in grades $4-7$ are small and medium entities that are allowed to tender for jobs ranging between R4 - 40 million, while contractors that fall in grades 1 3 are small enterprises which can bid on tenders less than or equal to R1.5 million [7].

\section{Motivation and Methodology}

Many previous researchers have studied the role of small scale businesses in national economies; however, the extent studies have focused on specific small scale sector is limited or has been postponed. This article seeks to provide a concise overview of the role of SSECs in national economies with specific reference to South Africa and highlight the significant role of SSECs in the economy as well as the challenges experienced by SSECs in the industry. There is little clarity on the extent to which SSECs in construction industry have been evaluated. This demonstrates that fewer researchers have done some work on the role of SSECs in South Africa and none in particular on this topic. Through the focus of this paper, it is perceived that the outcome would set a precedent for similar studies in other small scale businesses and this would give uniqueness to the future studies on small businesses. Data for the review were predominantly sourced from, University of South Africa databases, South African journals, overseas journals, online journals, South African media and CIDB databases.

\section{Current Trends in South African Construction Industry}

The industry initiatives are implemented through CIDB, the Construction Education and Training Authority and the Department of Public Works. The trends in the industry are largely shaped through these departments. The indicators that can be used to assess industry drivers include the economic outputs such as GDP, state of the infrastructure, construction businesses and employment. Each of the drivers thus tells a 
story relevant to the understanding of the state of the industry [8]. The current trends in the construction industry relate to the state of the infrastructure and [9] attributed this to uncontrollable forces by the industry. The current industry situation is shaped by the external forces including the housing backlog, which has led to urban shanty houses and poverty. As observed by [9], there is no appropriate sanitation, inadequate water facilities, insecurity of tenure, poor quality of house and living space. In Johannesburg for instance, demand for houses has grown tremendously due to population increase as many people move into the city [10]. However, the government is working towards eradicating these informal settlements. The other driver relates to the infrastructure as the government intends to improve on aging national infrastructure. This demonstrates that many types of infrastructure are needed in South Africa to support the growing population. The government policies tend to keep the construction industry busy as a way of creating and protecting jobs as well as stimulating economic growth. As a result, the existence of SSECs in these developments is vital.

\subsection{Emerging Contractors in Emerging Economies}

The construction industry has an important role in promoting economic growth and sustainable infrastructure of many economies throughout the world and emerging economies in Africa are no exception. In these economies, SSECs are essential vehicles which attend to the construction of schools, residential houses, roads, bridges, power infrastructures and dams. By so doing, they create jobs and contribute towards economic growth. The infrastructure is essential as it provides social and welfare to the nation. In Zambia, the construction industry contributed $8 \%$ in 2003 and had employment increase from 140,000 in 2000 to 150,000 in 2001 [11]. The author in [12] reported that in Ghana, $90 \%$ of companies registered are micro, small and medium and these companies are important for economic growth of that country and major sources of employment [13].

The SSECs employ few permanent staff, usually less than 10 employees [14] while the rest of their employees are operated on casual labour, based on need requirement. The contractors lack equipment and tools that include tipping trucks, graders, bulldozers, pick-up trucks, loaders and tractors. Old equipment is often used in construction which results in frequent breakdowns and routine maintenance. The author in [15] states that notwithstanding such limitations, SSECs in their local sphere of influence often have the ability to carry out small sized projects and should compete at that level. The spread of work between large, medium and SSECs is dominated by large construction enterprises which control more than 50 percent of the category [16]. However, SSECs dominate and control of small activities though the turnover per enterprise is minimal.

\subsection{The Role of SSECs in South Africa}

Although the role of SSECs is a controversy [2], in South Africa, they assist in the provision of physical infrastructure, engage in projects that generate new buildings and refurbish existing ones for a variety of clients [6]; [17]. SSECs provide buildings used in the production of goods in the economy, engage in building residential and non-resi- 
dential structures such as houses, industrial and commercial buildings. For those that are engaged in civil engineering, they construct schools, roads, hospitals, culverts, bridges, and projects related to national infrastructure [10]. Based on the significant role as outlined, SSECs in South Africa are expected to become the main players in economic transformation and growth, job creation and income generation. As such, since 1994, the government has been putting measures as a way of creating an enabling environment for these contractors to survive [18]. Other important roles of SSECs to the South African economy relate to the gross domestic product (GDP), investment and the volume of labour [9]; [19]. The author in [20] reported that SSECs contribute significantly towards the industry's $35 \%$ to the total gross domestic fixed investment. The construction industry has the second largest percentage of small and medium enterprises (SME) (12\%), after services industry [21], as shown in Figure 1. The public sector is a major contributor to infrastructural development, accounting for around R150 billion in civil projects, R25 billion in residential and non-residential building works annually [22].

In terms of employment, SSECs employ the majority of construction workers. The total number of people employed in the construction industry in 2012 was approximately 986,000 [23], as indicated in Table 1, in which Gauteng Province had the highest figure (27\%) and Northern Cape the lowest (2\%).

When compared to large companies which rely on automation in their operations, SSECs remain a sustainable source of employment creation as they have the potential to build viable construction companies and develop skills. Based on the role played by SSECs to the South African economy, the government and construction sector have engaged in processes that redirected the industry's growth and performance as a way of supporting the country's social and economic transformation agenda [24]. These contractors operate at local and metro level, on which severe competition undermines sustainability and consolidation [25]. Unfortunately, SSECs cannot tender for large projects

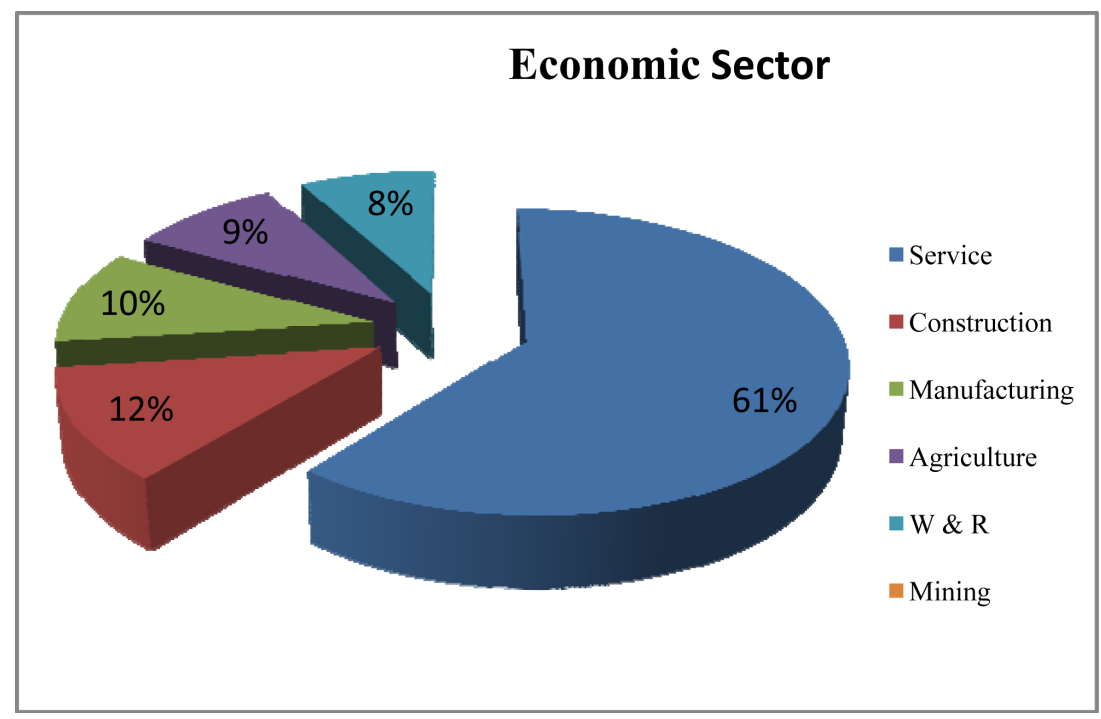

Figure 1. Sector classification of SEDA's existing clients. Source: Ref: [21]. 
as these cannot be subdivided to accommodate SSECs, this is a condition set within CIDB grading system. Such projects require a high level of management, financial solvency and technical capability [7]; [26]. This defines the qualities and skills frequently found amongst large contractors [26]. Table 2 shows classes of works and number of enterprises per grade.

The contribution of SSECs to South Africa's economic development has been a focus of discourse for a number of years [27]. At policy level, the strategies relating to the construction industry are in favour of SSECs [7], however, the development and performance of SSECs in terms of growth and profitability has remained a concern to the policymakers and business executives [7]; [14]; [28].

\subsection{Challenges Facing SSECs}

While the role of SSECs to economic development is generally acknowledged, the con-

Table 1. Employment, construction by province 2012 .

\begin{tabular}{ccc}
\hline Province & Employment (2012) & Percentage \\
\hline Western Cape & 135,000 & 14 \\
Eastern Cape & 108,000 & 11 \\
Northern Cape & 19,000 & 2 \\
Free State & 47,000 & 5 \\
Kwa Zulu Natal & 210,000 & 21 \\
North West & 46,000 & 5 \\
Gauteng & 265,000 & 27 \\
Mpumalanga & 64,000 & 6 \\
Limpopo & 92,000 & 9 \\
Total & 986,000 & 100 \\
\hline
\end{tabular}

Source: Ref: [23].

Table 2. Number of enterprises and class of works.

\begin{tabular}{cccccccc}
\hline Designation & CE & EE & PE & GB & ME & SW & Total \\
\hline 1 & 23,268 & 1313 & 4051 & 50,998 & 4227 & 15,389 & 99,246 \\
2 & 1499 & 113 & 119 & 2032 & 217 & 497 & 4477 \\
3 & 639 & 82 & 86 & 597 & 92 & 135 & 1631 \\
4 & 788 & 132 & 201 & 811 & 151 & 154 & 2237 \\
5 & 681 & 133 & 265 & 636 & 212 & 255 & 2182 \\
6 & 738 & 41 & 79 & 614 & 85 & 73 & 1630 \\
7 & 234 & 29 & 47 & 223 & 44 & 36 & 613 \\
8 & 86 & 7 & 15 & 86 & 18 & 14 & 226 \\
9 & 47 & 2 & 21 & 31 & 21 & 19 & 141 \\
Total & $\mathbf{2 7 , 9 8 0}$ & $\mathbf{1 8 5 2}$ & $\mathbf{4 8 8 4}$ & $\mathbf{5 6 , 0 2 8}$ & $\mathbf{5 0 6 7}$ & $\mathbf{1 6 , 5 7 2}$ & $\mathbf{1 1 2 , 3 8 3}$ \\
\hline
\end{tabular}

Key: GB: General Building, CE: Civil Engineering, ME: Mechanical Engineering, EE: Electrical Engineering, PE: Plumbing Engineering, SW: Specialist Works. Source: Ref: [6]. 
tractors are faced with many challenges that limit their growth and profitability. The author in [2] note that the construction industries around the world face many difficulties and challenges, however, the challenges become more significant and complex especially in African countries and other developing countries. In developing countries, SSECs still face challenges such as lack of skills, financial instability, shortages of resources and failure by contractors to deal with external forces [9]; [29]. These challenges make some SSECs unable to sustain operational performance beyond the startup phase [30]. As a result, in some cases, as reported by [14] SSECs often do not finish work within agreed terms as work is stopped, abandoned or suspended before completion. Accordingly, SSECs have been accused of failing to meet contract terms which they enter into resulting in their performance being dominated by clients dissatisfied owing to poor quality of work, inappropriate defects and delayed project delivery [22]. Even though their role is significant, this suggests weak performance and becomes a binding constraint to SSECs' growth and profitability. The challenges encountered by SSECs in South Africa that impede growth and profitability include:

- The inability of SSECs to access the right type of finance which is vital for them to operate and grow. SSECs face more difficulties in accessing finance from banks [14].

- Late payment is a challenge for SSECs in construction businesses. Late payment of completed work, results in contractors halting work unless payment for completed work has been processed after the agreed date [28].

- There are more demands from more knowledgeable and better organised clients and other stakeholders.

- Lack of adequately qualified staff to effectively execute projects, hampers the performance of SSECs works [27].

- There are more regulations in efforts to address environmental, health and safety concerns in South Africa [7].

- There is intensive competition from large construction companies offering similar and diversified services [25].

- The contractors do not have adequate technical training, business culture, capacity or maturity [7]; [26], and so are not able to provide acceptable quality of work.

- SSECs find it difficult to access the required equipment. Leasing and purchasing of equipment are not feasible options due to costs and collateral required.

- Challenges of interpreting the Joint Building Contracts Committee (JBCC).

The challenges highlighted above are supported in a subcontracting survey conducted by [31], which shows that contractors at times terminate relationships with subcontractors due to poor track record in managing cash flows, inability to complete the apportioned work, overpricing work, and failure to pay labour, disputes about payment and poor health and safety management. Also the clause of "pay when paid" applied in the industry has been cited in the study as another challenge encountered by SSECs in the industry. The challenges encountered by SSECs in South Africa are similar to those which are commonly seen in reports on the industries in other emerging economies, for example: [32] noted that the challenges in the industry can be classified into inadequacies in industry infrastructure, inefficiencies and incompetence from clients and con- 
sultants. In other studies, [33] found challenges relating to poor budgetary and time control experienced by SSECs, while [34] also found challenges of poor estimation, improper techniques and tools, incompetent designers, change management, social and technological issues and site related issues as having negative impact on the performance of SSECs. On the other hand, [35] cited unrealistic target setting and deviation that originate from the client as some challenges encountered by SSECs.

\subsection{Promotion of SSEC's by the South African Government}

Considering the important role played by SSECs in South Africa, the government has initiated development programmes to encourage a wider participation of SSECs in the construction industry [36]. Some of these programmes are emerging contractor development models (ECDMs) and emerging contractor development programmes (ECDPs) [29]. The former refers to a structured methodology that comprises measures designed to help SSECs develop the technical and management skills required to grow businesses [37]. However, a review of literature shows that no one model for contractor development suits all contractor categories [7]. Table 3 shows the different models that are appropriate to different levels of development.

\section{Conclusions and Recommendations}

In spite of the challenges encountered by SSECs in South Africa, SSECs continue to be a vital component of the economy in terms of job creation, income generation, poverty reduction, contribution to the GDP, source of entrepreneurship and innovation. SSECs are well placed to benefit from the opportunities presented by the government as important programs have been developed or are underway to remove barriers on financial challenges, skills shortages, weak policies and rules that inhibit them to realise their potential. Based on the analysis, the recommendations are:

- The South African government needs to develop a clear and more comprehensive small business contracting policies. The solution required to develop SSECs should

Table 3. Combined models.

\begin{tabular}{|c|c|}
\hline Model & Description \\
\hline EPWP & $\begin{array}{c}\text { Learner ship type models meant for the development of the Grade } 1 \text { and } 2 \text { construction } \\
\text { workforce }\end{array}$ \\
\hline ECDP & Emerging Contractor Development Programmes meant for Grade 2 to 3 SSECs \\
\hline EDPs & $\begin{array}{c}\text { Enterprise Development Programmes for, typically, contractors in Grades } 3 \text { to } 6 \text { who exhibit } \\
\text { potential to develop }\end{array}$ \\
\hline IECDM & $\begin{array}{l}\text { Realised in the improvement of business management skills, tendering skills, business growth, } \\
\text { CIDB grading and increased employment chances }\end{array}$ \\
\hline SACEM & $\begin{array}{l}\text { Programmes focusing on improving the performance of established contractors in, typically, } \\
\text { Grades } 4 \text { to 7, such as the Contractor Incubator Programme in line with the SA Construction } \\
\text { Excellence Model }\end{array}$ \\
\hline
\end{tabular}

Key: EPWP_Extended Public Works Programme, ECDP_Emerging Contractor Development Programme, EDP_ Enterprise Development Programme, IECDM-Integrated Emerging contractor development model and, SACEMSouth African Construction Engineering Model. Source: Ref: [38]. 
focus on getting the policies right.

- The skills shortage can be improved by providing a better trained workforce and hold training agencies accountable for meeting SSECs goals.

- The cost of finance and the conditionality tied to the loans of SSCEs are the main hindrances to access finance and this need to be removed to increase access to finance. This would stimulate growth and profitability.

- The government needs to enact legislation that protects SSECs against the delay in receiving payments from the clients.

- The competitiveness of an individual SSEC is strongly related to the quality of its owner, thus individual owners need to improve their individual human capital in form of formal education and training. This would improve their individual management capabilities.

\section{References}

[1] Osei, V. (2013) The Construction Industry and Its Linkages to the Ghanaian EconomyPolices to Improve the Sector's Performance. International Journal of Development and Economic Sustainability, 1, 56-72.

[2] Ofori, G. (1990) The Construction Industry: Aspects of Its Economics and Management. Singapore University Press, Singapore City.

[3] Akiner, I. M. and Akiner, E. (2009) Evaluation of Turkish Construction Industry through the Challenges and Globalization. Organization, Technology and Management in Construction an International Journal, 1, 64-71.

[4] The Republic of South African Act of Parliament, 38 of 2000.

[5] Department of Trade and Industry (2002) Small Business Development Guide. Department of Trade and Industry, Government Printer, Pretoria.

[6] Construction Industry Development Board (CIDB) (2010) National Register of Contractors. www.Cidb.org.za

[7] Greyling, E. (2012) Opportunities for Employment Creation through SME Development in the Construction Sector, Free State. International Labour Organisation, Geneva.

[8] Pearce, D. (2003) The Social and Economic Value of Construction: The Construction Industry's Contribution to Sustainable Development. www.ncrisp.org.uk

[9] Rust, F.C. and Koen, R. (2011) Positioning Technology Development in the SA Construction Industry: A Technology Foresight Study. Journal of the SA Institution of Civil Engineering, 53, 2-8.

[10] Horta, I.A., Camanho, A.S., Johnes, J. and Johnes, G. (2012) Performance Trends in the Construction Industry Worldwide: An Overview of the Turn of the Century. Journal of Productivity Analysis, 39, 89-99. http://dx.doi.org/10.1007/s11123-012-0276-0

[11] Uriyo, A.G., Mwila, J. and Jensen, L. (2004) Development of Contractor Registration Scheme with a Focus on Small Scale Civil Works Contractors. National Council for Construction, Lusaka.

[12] Mensah, S. (2004) A Review of SME Financing Scheme in Ghana. A Journal Presented at the UNIDO Regional Workshop of Financing Small MEDIUM Scale Enterprises, Accra, 15-16 March 2004, 1-19.

[13] Hinson, R.E and Mahmoud, M.A. (2011) Qualitative Insights into Market Orientation in Small Ghanaian Businesses. International Journal of Marketing Studies, 3, 35-44. 


\section{http://dx.doi.org/10.5539/ijms.v3n1p35}

[14] Twala, W.D. and Mvubu, M. (2009) Problems Facing Small and Medium Size Contractors in Swaziland. Journal Service Science and Management, 2, 353-361. http://dx.doi.org/10.4236/jssm.2009.24042

[15] Ofori, G. (2000) Challenges of Construction Industries in Developing Countries: Lessons from Various Countries. Conference Papers, 2nd International Conference on Construction in Developing Countries: Challenges Facing the Construction Industry in Developing Countries, 15-17 November 2000, Gabarone, 1-13.

[16] Van Wyk, L., Kolev, M., Osburn, L., de Villers, A. and Kimmie, Z. (2011) The Employment Aspects of Energy Related Improvements in Construction in South Africa. International Labour Organisation, Geneva.

[17] Marx, H.J. (2012) Construction Industry Indicators Affecting Contractors. Journal for the Advancement of Performance Information and Value, 4, 119-132.

[18] Hauptfleisch, D., Lazarus S., Knoetze, T. and Liebenberg, S. (2007) An Integrated Emerging Contractor Development Model for the Construction Industry: Practical Implementation and Statistical Quantification. www.irbnet.de/daten/iconda/CIB5292.pdf

[19] Ofori, G. (2006) Productivity of the Construction Industry. Research Brief 2005/2003, Department of Building, School of Design and Environment, National University of Singapore, Singapore.

[20] Department of Public Works (1999) Creating and Enabling Environment for Reconstruction, Growth and Development in the Construction Industry. The White Paper, Government, Pretoria, South Africa.

[21] Small Enterprise Development Agency (SEDA) Annual Review of Small Business in SA, 2011/2012. SEDA, Pretoria.

[22] Construction Industry Development Board (CIDB) (2012) The Construction Industry as a Vehicle for Contractor Development and Transformation. CIDB, Pretoria.

[23] Snyman, E. (2012) The State of the SA Construction Industry. www.industryinsight.co.za

[24] Construction Industry Development Board (CIDB) (2004) Construction Industry Status Report 2004: Synthesis Review on the South African Construction Industry and Its Development. CIDB, Pretoria.

[25] Construction Industry Development Board (CIDB) (2014) Quarterly Monitor. CIDB, Pretoria.

[26] Windapo, A. and Cattell, K. (2011) Research Report: Mapping the Path to Becoming a Grade 9 Contractor. Department of Construction Economics and Management, University of Cape Town, Cape Town.

[27] Atkinson, D., Ntema, L., Pappin, M., Gouveia, A. and Venter, A. (2012) Review of the Efficiency and Effectiveness of Past and On-Going SME Development Initiatives in the Free State Province. International Labour Organization.

[28] Baloyi, L. and Bekker, M. (2011) Causes of Construction Cost and Time Overruns: The 2010 FIFA World Cup stadia in SA. Acta Structilia, 18, 51-67.

[29] Buys, F. and Ludwada, D. (2012) The Potential of Built Environment Professionals' Contribution towards Emerging Contractor Development. Acta Structilia, 19, 74-89.

[30] Herrington, M., Kew, J. and Kew, P. (2010) Tracking Entrepreneurship in South Africa: A GEM Perspective. SA GEM Report, Graduate School of Business, Cape Town.

[31] Construction Industry Development Board (CIDB) (2013) Subcontracting in the SA Con- 
struction Industry; Opportunities for Development. www.Cidb.org.za

[32] Ogunlana, S.O., Promkuntong, K. and Jearkjirm, V. (1996) Construction Delays in a Fast-Growing Economy: Comparing Thailand with Other Economies. International Journal of Project Management, 14, 37-45. http://dx.doi.org/10.1016/0263-7863(95)00052-6

[33] Okuwoga, A.A. (1998) Cost-Time Performance of Public Sector Housing Projects in Nigeria. Habitat International, 22, 389-395. http://dx.doi.org/10.1016/S0197-3975(98)00014-9

[34] Long, N.D., Ogunlana, S., Quan, T. and Lam, K.C. (2004) Large Construction Projects in Developing Countries: A Case Study from Vietnam. International Journal of Project Management, 22, 553-561. http://dx.doi.org/10.1016/j.ijproman.2004.03.004

[35] Navon, R. (2005) Automated Project Performance Control of Construction Projects. Automation in Construction, 14, 467-476. http://dx.doi.org/10.1016/j.autcon.2004.09.006

[36] Gasa, Z.B.N. (2012) Measuring the Competitiveness of Small, Medium and Micro Enterprise Contractors through the Use of the Register of Contractors. PhD Thesis, Nelson Mandela Metropolitan University, Port Elizabeth.

[37] Dlungwana, W.S and Rwelamila, P.D. (2005) Constructor Development Models for Promoting Sustainable Building-A Case for Developing Management Capabilities of Contractors. Proceedings of the 2005 World Sustainable Building Conference, Tokyo, 27-29 September, 4208-4215.

[38] Hove, G. and Banjo, A.O. (2015) Performance in the Construction Industry-A Conceptual and Theoretical Analysis. Open Journal of Business and Management, 3, 177-184.

\section{Submit or recommend next manuscript to SCIRP and we will provide best service for you:}

Accepting pre-submission inquiries through Email, Facebook, LinkedIn, Twitter, etc.

A wide selection of journals (inclusive of 9 subjects, more than 200 journals)

Providing 24-hour high-quality service

User-friendly online submission system

Fair and swift peer-review system

Efficient typesetting and proofreading procedure

Display of the result of downloads and visits, as well as the number of cited articles

Maximum dissemination of your research work

Submit your manuscript at: http://papersubmission.scirp.org/ 